\title{
Using CFD Surface Solutions to Shape Sonic Boom Signatures Propagated from Off-Body Pressure
}

\author{
Irian Ordaz* and $\mathrm{Wu} \mathrm{Li}^{\dagger}$ \\ NASA Langley Research Center, Hampton, VA 23681
}

\begin{abstract}
The conceptual design of a low-boom and low-drag supersonic aircraft remains a challenge despite significant progress in recent years. Inverse design using reversed equivalent area and adjoint methods have been demonstrated to be effective in shaping the ground signature propagated from computational fluid dynamics (CFD) off-body pressure distributions. However, there is still a need to reduce the computational cost in the early stages of design to obtain a baseline that is feasible for low-boom shaping, and in the search for a robust low-boom design over the entire sonic boom footprint. The proposed design method addresses the need to reduce the computational cost for robust low-boom design by using surface pressure distributions from CFD solutions to shape sonic boom ground signatures propagated from CFD off-body pressure.
\end{abstract}

\section{Nomenclature}

$\begin{array}{ll}\text { Acronyms } & \\ \text { BOSS } & =\text { boom optimization using smoothest shape (a computer code for low-boom design) } \\ \text { CFD } & =\text { computational fluid dynamics } \\ \text { Symbols } & =\text { equivalent area } \\ A_{\mathbf{e}} & =\text { classical equivalent area based on Mach tangent cutting planes for the baseline configu- } \\ A_{\mathbf{e}, \text { baseline }}^{\text {Mach }} & \text { ration } \\ A_{\mathbf{e}, \text { design }}^{\text {Mach }} & =\text { classical equivalent area based on Mach tangent cutting planes for the design configuration } \\ A_{\mathbf{e}, \text { mixed }} & =\text { reversed equivalent area prediction for the design configuration } \\ A_{\mathbf{e}, \text { baseline }}^{\text {reversed }} & =\text { reversed equivalent area for the design configuration } \\ d p / p & =\text { off-body pressure distribution }\end{array}$

\section{Introduction}

CONCEPTUAL design of a low-boom and low-drag supersonic aircraft remains a challenge despite sig$\bigcup$ nificant progress in recent years. Accurate prediction of sonic boom signatures using CFD requires the computation of the pressure field several body lengths below the aircraft, where three-dimensional aerodynamic effects have been resolved. The off-body pressure calculation is currently a bottleneck for low-boom optimization of supersonic configurations. In this paper, the low-boom design methods in literature are classified into three categories, and described below.

Several papers have demonstrated the capability to perform design optimization of a low-boom supersonic aircraft but with only a limited number of design variables due to the high computational cost associated with off-body pressure sensitivity calculation [1-4]. One exception to this by Li and Rallabhandi [5] demonstrated an inverse design optimization consisting of 120 variables and using volume equivalent area sensitivity with a tool called BOSS [6]. However, the method is limited to volume shaping and can only be applied when the configuration is close to a low-boom design.

*Research Engineer, Aeronautics Systems Analysis Branch, Systems Analysis and Concepts Directorate.

†Senior Research Engineer, Aeronautics Systems Analysis Branch, Systems Analysis and Concepts Directorate. 
Another approach, known as the multipole method [7,8], can reduce the cost of off-body pressure calculations by extrapolation of near-field pressure to the mid-field. The near-field pressure is computed close to the body before the three-dimensional aerodynamic effects are fully resolved. Although less computationally demanding, this approximation method still requires the computation of off-body pressure distributions $(d p / p)$ using CFD.

The adjoint methods [9-11] for obtaining design sensitivities allow optimization with a large number of design variables. Despite requiring the computation of a pressure distribution several body lengths below the aircraft, it is capable of computing design sensitivities efficiently for a large number of design variables using a single flow and adjoint solution for each design objective. The capability to design with a large number of design variables allows for greater design freedom.

Three key technical challenges remain which are addressed by the proposed design method. The first of these challenges is the requirement of off-body pressure calculations for low-boom shaping. The second challenge is the need for major shape changes (such as wing planform changes) and rearrangement of vehicle components to obtain a feasible baseline in the early stages of the low-boom design process. Here, a feasible baseline means that the configuration can be shaped into a low-boom configuration by inverse design using reversed equivalent area or adjoint methods. Lastly, robust low-boom design over the entire sonic boom footprint for a supersonic aircraft is more costly than designing the under-track signature because of the additional cost of computing accurate off-body pressure distributions at off-track locations.

The remainder of the paper is organized into three sections. Sections II and III describe the new design method and several design case studies to verify and demonstrate the capabilities of the new method. Section IV is a summary of the practical implications of this work and a discussion of future work.

\section{Using CFD Surface Pressure for Off-Body Low-Boom Design}

This section describes the proposed design method that uses surface pressure distributions from CFD solutions to approximate the reversed equivalent area [5] of a configuration. The reversed equivalent area is computed from a CFD pressure distribution with fully resolved three-dimensional aerodynamic effects. The off-body pressure contours are given in Fig. 1 for an in-house low-boom demonstrator concept. The pressure distribution at an off-body location is propagated backward in time using the augmented Burgers' equation [12] and converted into an equivalent area. The reversed equivalent area is an accurate representation of the aircraft as a body-of-revolution that produces the same ground signature as the offbody pressure field with fully resolved three-dimensional aerodynamic effects. It has been verified $[1,5]$ that in practice, the ground signature propagated from the reversed equivalent area is the same as the ground signature propagated from the mid-field pressure distribution: two signatures have the same shape and same level of perceived loudness.

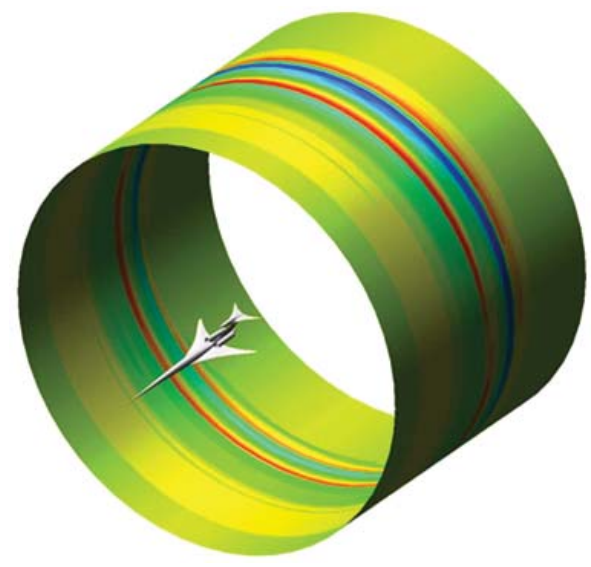

Figure 1. Off-body pressure distribution required for high-fidelity sonic boom analysis and design.

The main discovery is that the reversed equivalent area sensitivity to design changes can be accurately approximated by the sensitivity of the classical equivalent area based on surface pressure from CFD solutions. A mixed-fidelity equivalent area $\left(A_{\mathrm{e}, \mathrm{mixed}}\right)$ given by Eq. 1 is used to predict the reversed equivalent area of a new design configuration. Note that the mixed $A_{\mathrm{e}}$ is based on the reversed equivalent area $\left(A_{\mathrm{e}, \text { baseline }}^{\text {revers }}\right)$ and the Mach equivalent area $\left(A_{\mathrm{e}, \text { baseline }}^{\text {Mach }}\right)$ of the baseline configuration which requires 
only one off-body CFD solution for each design cycle. The evaluation of new designs requires only a CFD surface solution to calculate the Mach equivalent area $\left(A_{\mathrm{e}, \mathrm{design}}^{\mathrm{Mach}}\right)$.

$$
A_{\mathrm{e}, \text { mixed }}=A_{\mathrm{e}, \text { baseline }}^{\text {reversed }}-A_{\mathrm{e}, \text { baseline }}^{\mathrm{Mach}}+A_{\mathrm{e}, \mathrm{des} \text { gan }}^{\mathrm{Mach}}
$$

The flow diagram of the low-boom design process using the mixed-fidelity $A_{\mathrm{e}}$ is given in Fig. 2. First, a sonic boom analysis of the baseline configuration is performed, where the reversed equivalent area $\left(A_{\mathrm{e}, \text { baseline }}^{\text {reversed }}\right)$ is calculated using the off-body pressure distribution, and the Mach $A_{\mathrm{e}}$ is calculated using the Mach tangent cutting planes [13] of the CFD surface solution. A low-boom equivalent area target is then generated interactively for the reversed $A_{\mathrm{e}}$ of the baseline configuration. The design iteration process starts with the baseline geometry which is parameterized and deformed to match the low-boom $A_{\mathrm{e}}$ target. Here, a CFD surface solution is performed for the new design and the Mach $A_{\mathrm{e}}\left(A_{\mathrm{e}, \mathrm{design}}^{\mathrm{Mach}}\right)$ is calculated along with the mixed $A_{\mathrm{e}}$ as shown in Eq. 1. The design objective is to minimize the difference between the mixed $A_{\mathrm{e}}$, which is a prediction of the reversed $A_{\mathrm{e}}$ for the current design, and the low-boom $A_{\mathrm{e}}$ target. Once the mixed $A_{\mathrm{e}}$ for the design closely matches the desired target, the process starts again with the new design as the new baseline for the next design cycle.

The use of equivalent area as the sonic boom design metric is preferred because it relates directly to the volume arrangement of the configuration. This relationship allows the designer to make better informed decisions, and generate effective parametric schemes to achieve the design intent. The design process can also be expanded for robust design. Here, robust design is used to describe low-boom design at underand off-track locations. A robust design cycle requires one off-body CFD solution of the baseline at both under- and off-track locations but the evaluation of each new design requires only one CFD surface solution.

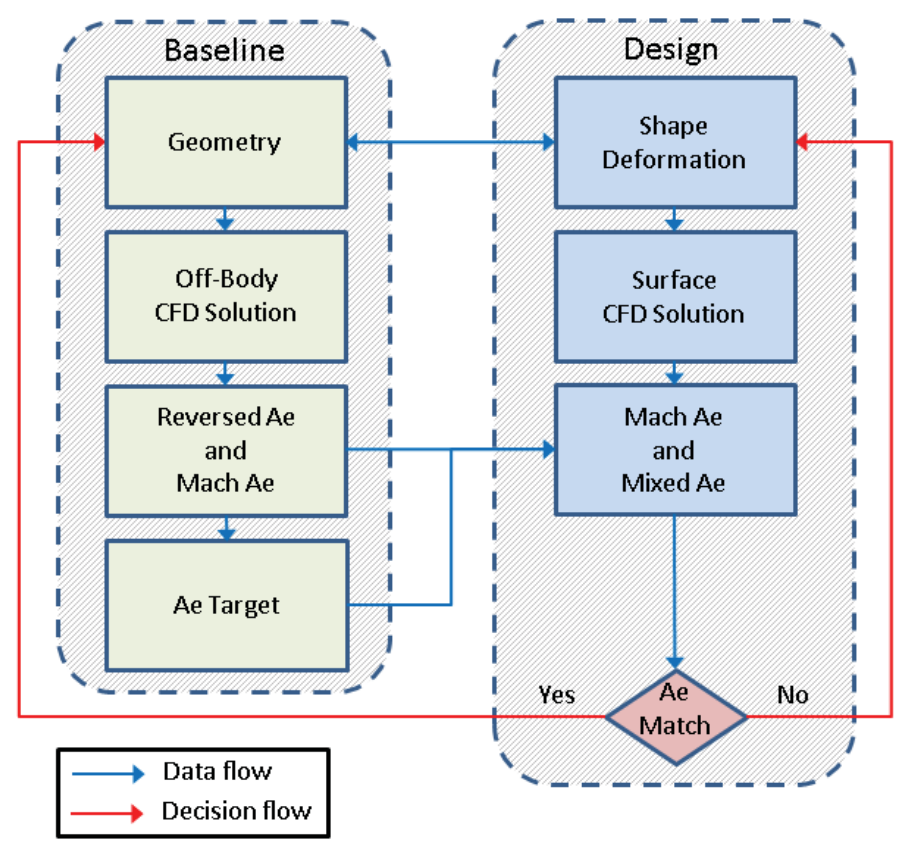

Figure 2. Mixed-fidelity design process.

\section{Verification Case Studies}

This section uses the in-house low-boom demonstrator concept with flow-through nacelles, documented in [1] and shown in Fig. 3, to verify and highlight the capabilities of the proposed design method. This includes verification of the accuracy of the classical equivalent area sensitivity to predict the sensitivity of the reversed equivalent area for under- and off-track low-boom design. The verification is conducted with three case studies including fuselage, wing, and horizontal tail shaping. The CFD analysis and the atmospheric propagation of off-body pressure distributions are conducted with Cart3D [14] and sBOOM [12], respectively. Note that the reversed equivalent area prediction for the deformed geometry in each verification case is labeled as the design. 

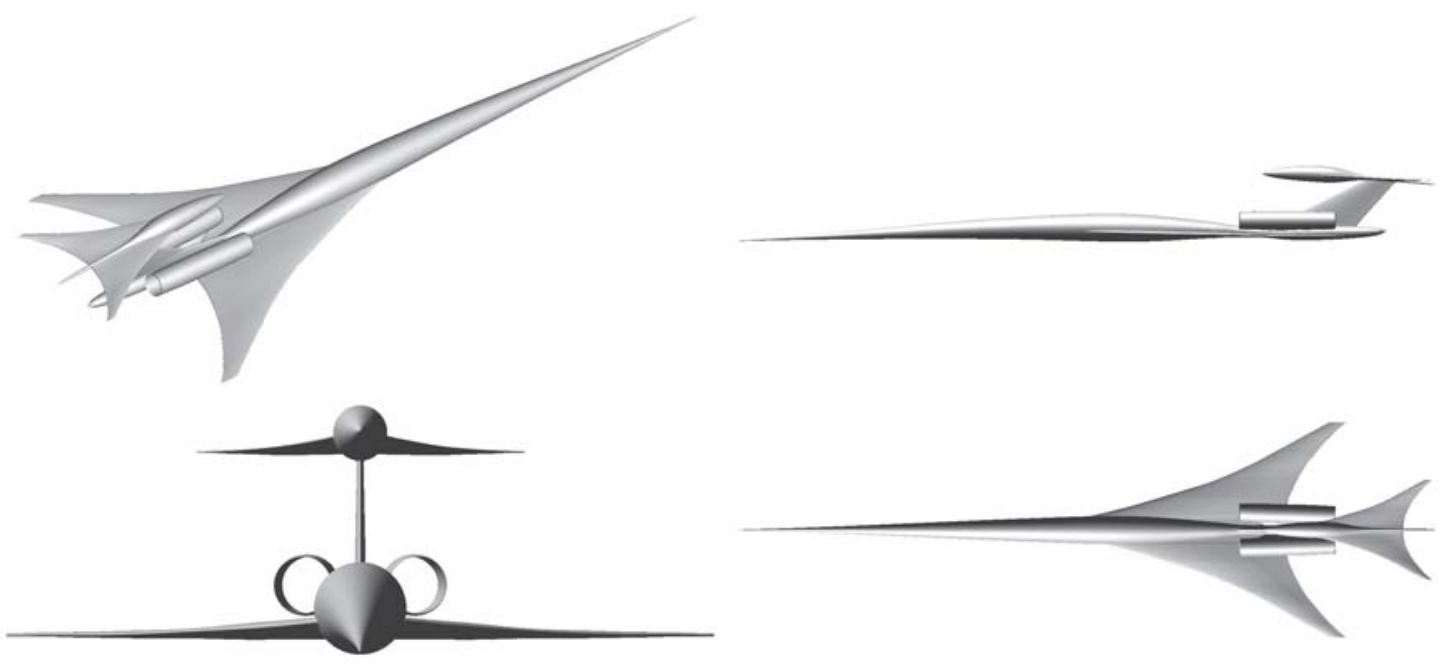

Figure 3. Baseline configuration.

\section{A. Verification of Wing Twist Deformation at Under- and Off-Track Locations}

The objective of the first case study is to verify the accuracy of the mixed $A_{\mathrm{e}}$ prediction for a wing twist deformation. The sonic boom characteristics are verified at the under-track and off-track location at an azimuth angle of $30 \mathrm{deg}$. The wing twist deformation, shown in Fig. 4, consists of a linearly varying twist along the entire wing span with no twist at the root airfoil and a 3 deg. twist (pitch down) at the tip airfoil.

The off-track sonic boom characteristics are obtained by calculating the mixed $A_{\mathrm{e}}$ distribution based on the Mach $A_{\mathrm{e}}$ sensitivity at the azimuth angle of $30 \mathrm{deg}$. Figures 5 and 6 show good agreement in the mixed $A_{\mathrm{e}}$ prediction at both under- and off-track locations. The implication of this result is that the mixed $A_{\mathrm{e}}$ design approach allows the robust (under- and off-track) design of supersonic aircraft with a single CFD surface solution. By calculating the Mach $A_{\mathrm{e}}$ of the design CFD surface solution for varying azimuth angles, it is possible to obtain the $A_{\mathrm{e}}$ sensitivity for a design change throughout the entire sonic boom footprint.

Figures A-1 and A-2 of the Appendix show the ground signatures corresponding to the equivalent area distributions in Fig. 5 and 6, respectively. As expected, the predicted under- and off-track ground signatures for the design also show good agreement with the ground signatures propagated from the Cart3D off-body pressure distributions.

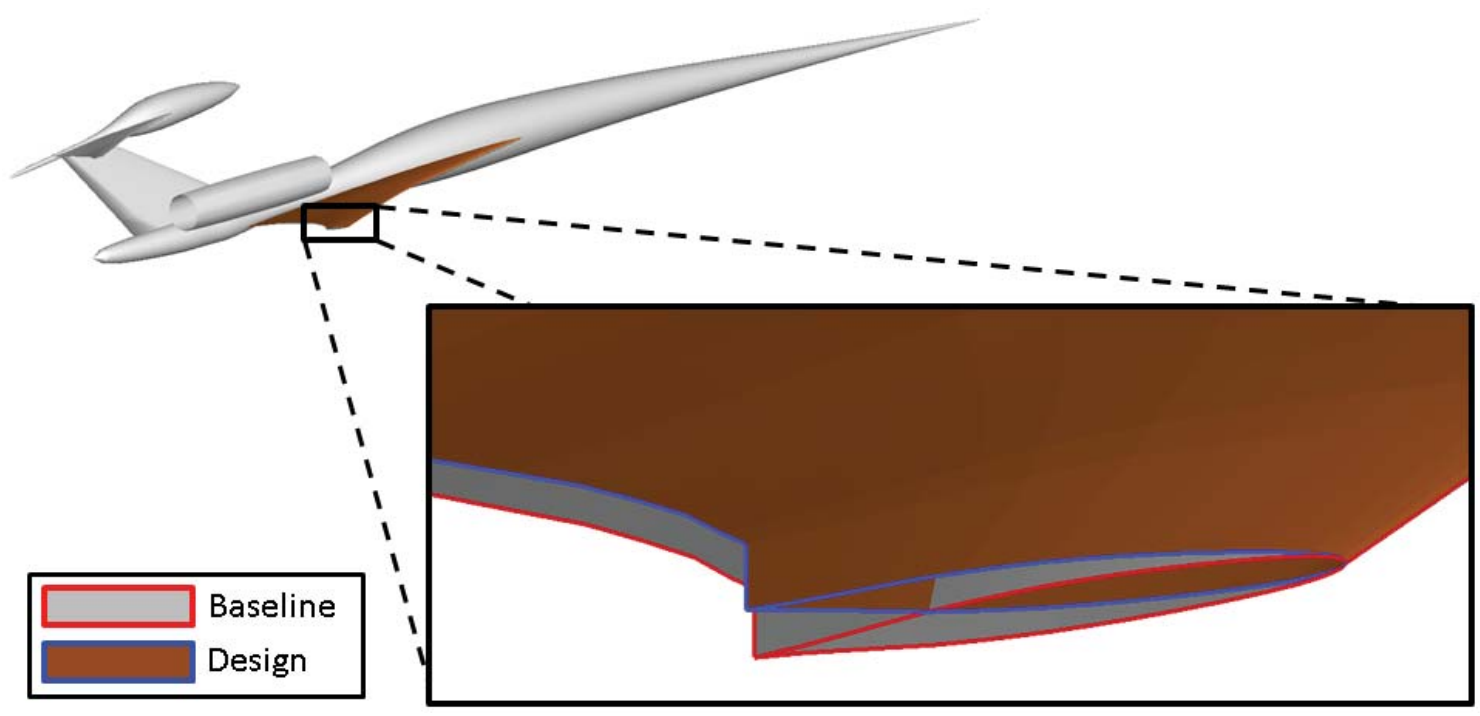

Figure 4. Wing twist deformation. 


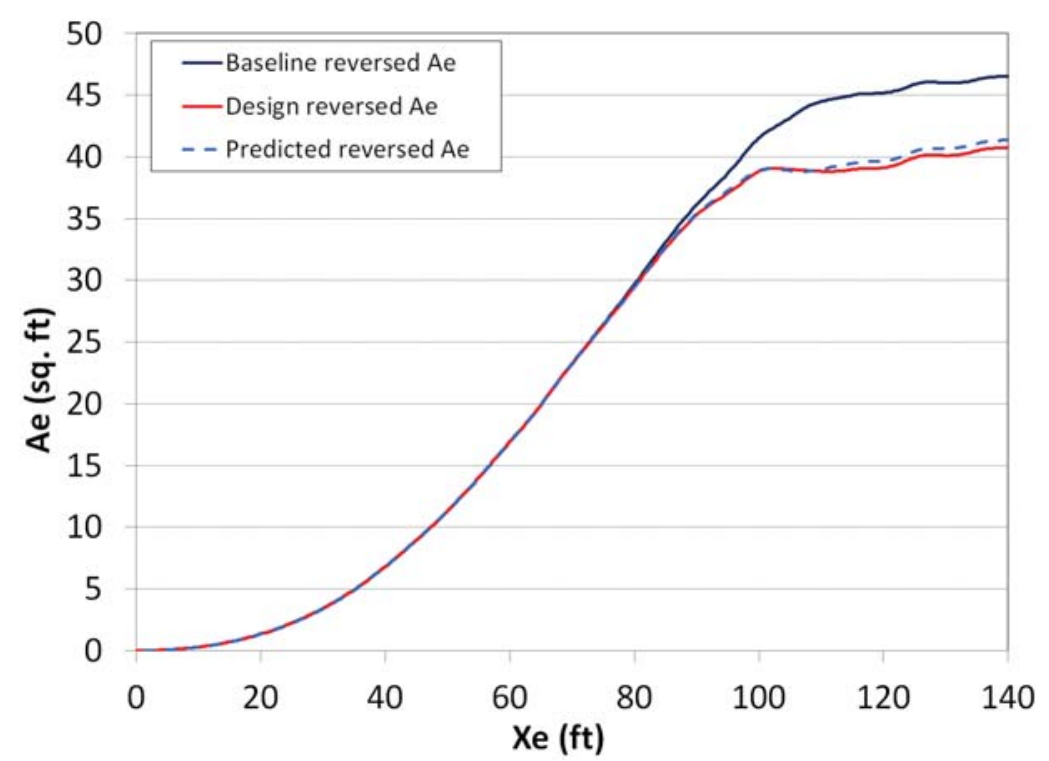

Figure 5. Under-track verification of reversed equivalent area prediction for a wing twist deformation.

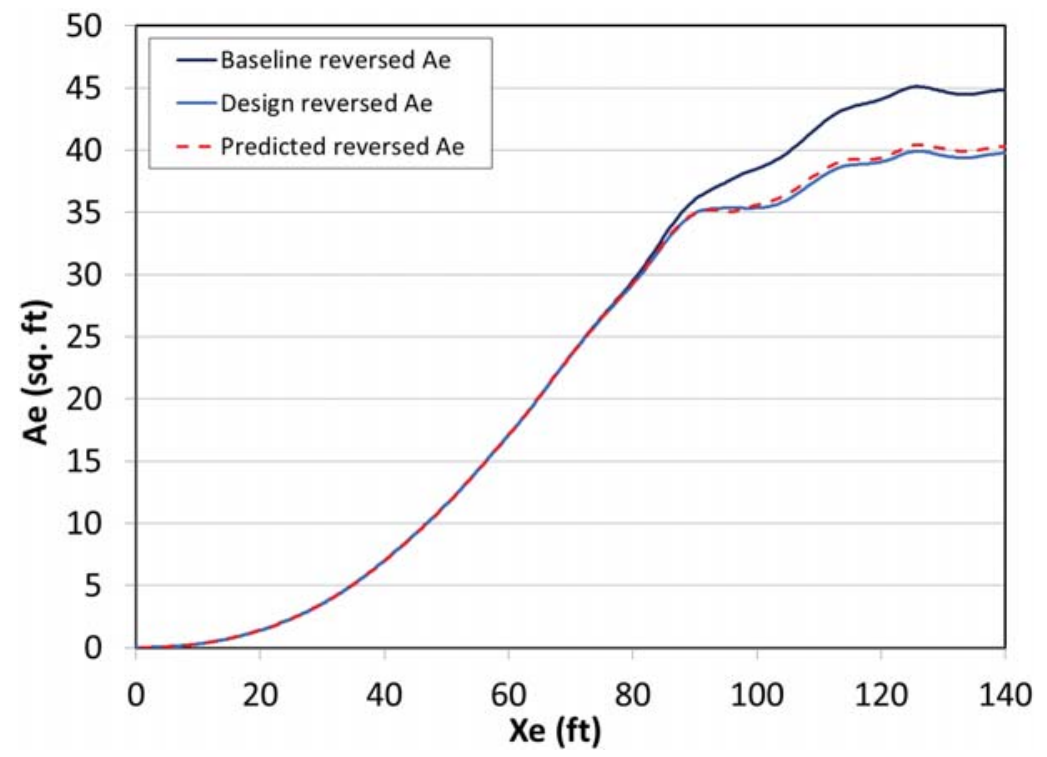

Figure 6. Off-track verification of reversed equivalent area prediction for a wing twist deformation.

\section{B. Verification of Horizontal Tail Camber Deformation}

The next case study is used to verify the accuracy of the mixed $A_{\mathrm{e}}$ prediction for aft lift tailoring with a horizontal tail in the presence of strong nacelle and tail shock interactions. The horizontal tail camber deformation is shown in Fig. 7. The deformation is performed by linearly varying the camber from a control point located at the midchord and midspan of the horizontal tail. The magnitude of the change at the control point is 10 percent of the local chord length and no change is allowed at the root and tip airfoils.

The equivalent area prediction for the camber deformation is given in Fig. 8. Here, the plot has been truncated to start at an equivalent length of $100 \mathrm{ft}$ to better show the prediction results. Once again, the mixed $A_{\mathrm{e}}$ is able to capture both the magnitude and shape of the change in the actual reversed $A_{\mathrm{e}}$ despite the complex shock interactions which exist aft of the nacelles. The corresponding ground signatures are provided in Fig. A-3 of the Appendix. Note that the predicted ground signature shows excellent agreement with the ground signature of the design which is propagated from the Cart3D off-body pressure distribution. The accuracy of the off-body pressure distribution several body lengths away from 
the aircraft becomes more important as the design focus shifts aft because of the increasing complexity of the flowfield. The result of this verification study is important because it is now possible to tailor the sonic boom characteristics in the aft region with a less computationally expensive CFD surface solution.

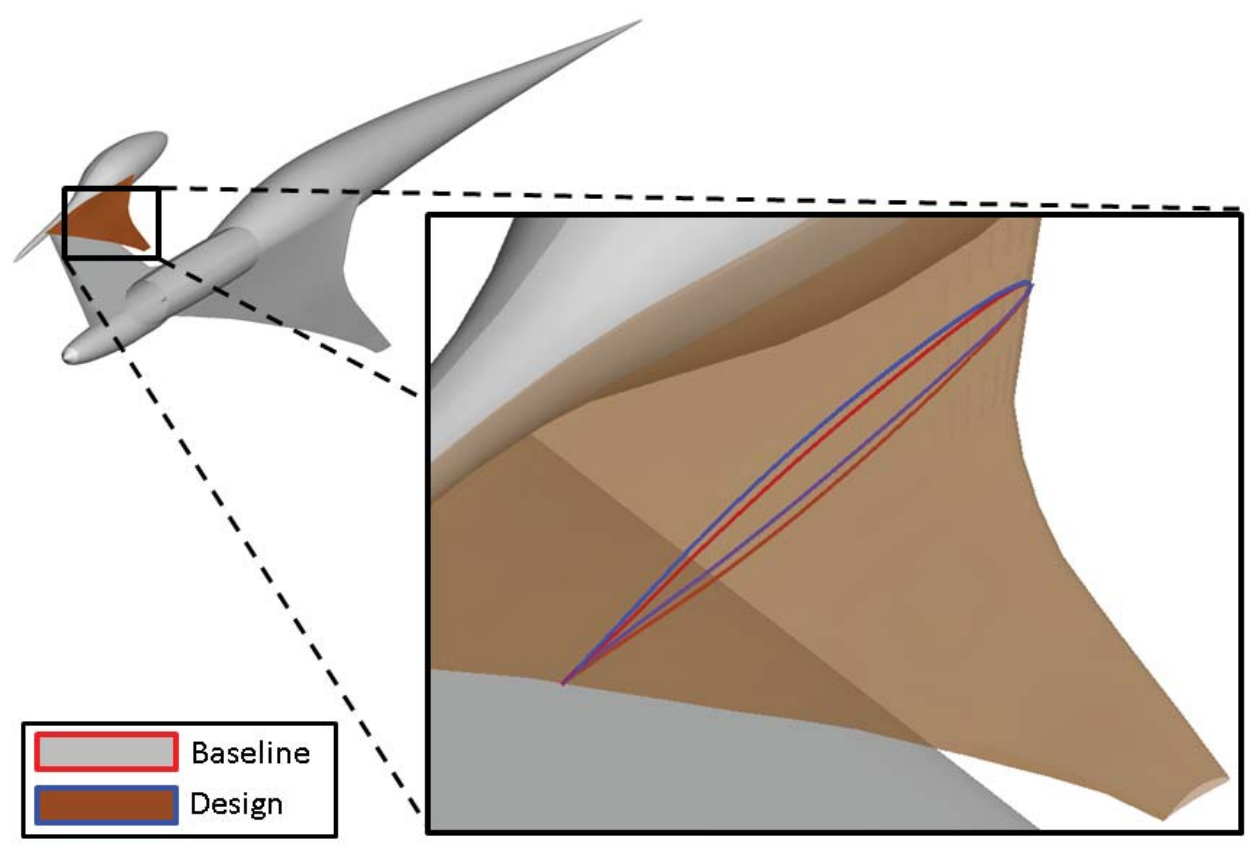

Figure 7. Horizontal tail camber deformation.

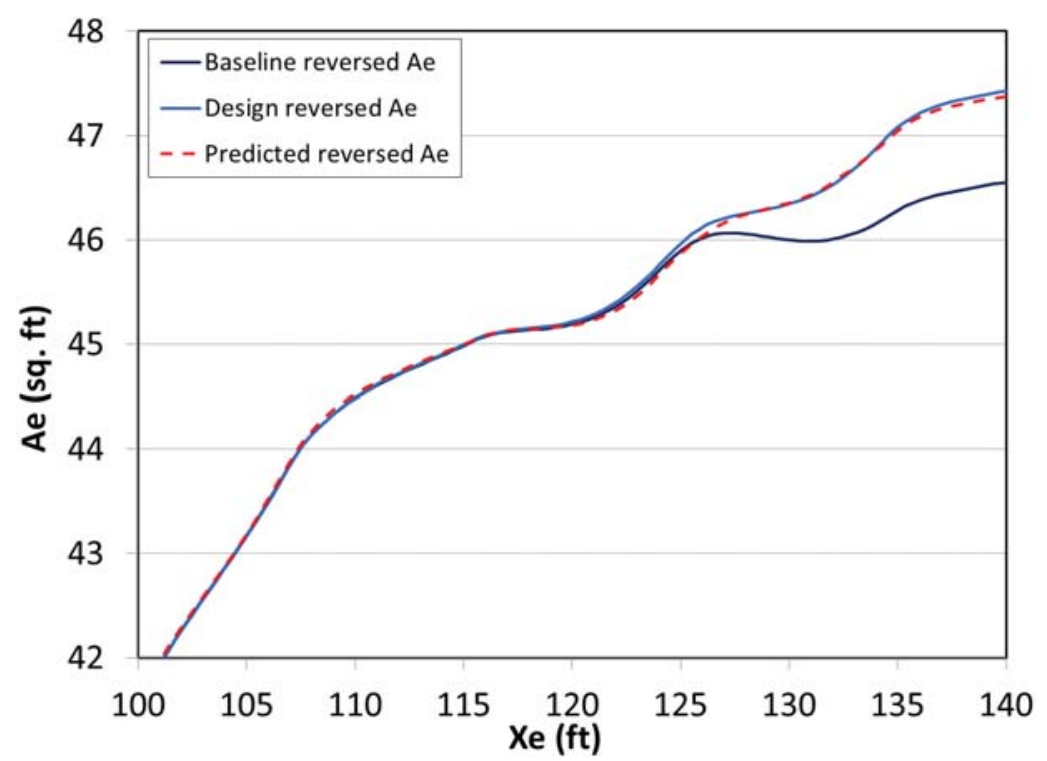

Figure 8. Verification of reversed equivalent area prediction for a camber deformation of the horizontal tail.

\section{Verification of Shielding Effects for a Fuselage Deformation}

The last case study is used to verify that the shielding effect of the main wing at the under-track location can be accurately predicted by the mixed $A_{\mathrm{e}}$ for a deformation on the upper region of the fuselage. Here, the change in reversed equivalent area at the under-track is expected to be small as a result of shielding. The deformation is created by increasing the upper fuselage thickness by $0.2 \mathrm{ft}$ (4.5 percent of the local diameter) at an $x$-location of $77 \mathrm{ft}$ and the thickness is allowed to vary between the range of $x=74$ and $x=80 \mathrm{ft}$. A comparison of the baseline and the deformed geometry (denoted as the design) is given in 
Fig. 9. The location of the fuselage deformation results in a shock and expansion that is shielded from the under-track by the wing as shown in Fig. 10.

A comparison of the predicted and actual reversed $A_{\mathrm{e}}$ for the fuselage deformation is given in Fig. 11. The plot has been truncated to start at an equivalent length of $90 \mathrm{ft}$ to better show the region of change. The reversed $A_{\mathrm{e}}$ distributions for the baseline and the design are computed from the under-track off-body pressure distribution at three body lengths below the aircraft. The reversed $A_{\mathrm{e}}$ of the design, which would otherwise require a more computationally expensive CFD-based off-body pressure solution is predicted with the mixed $A_{\mathrm{e}}$ distribution (denoted by dashed red lines) at the cost of a single CFD surface solution.

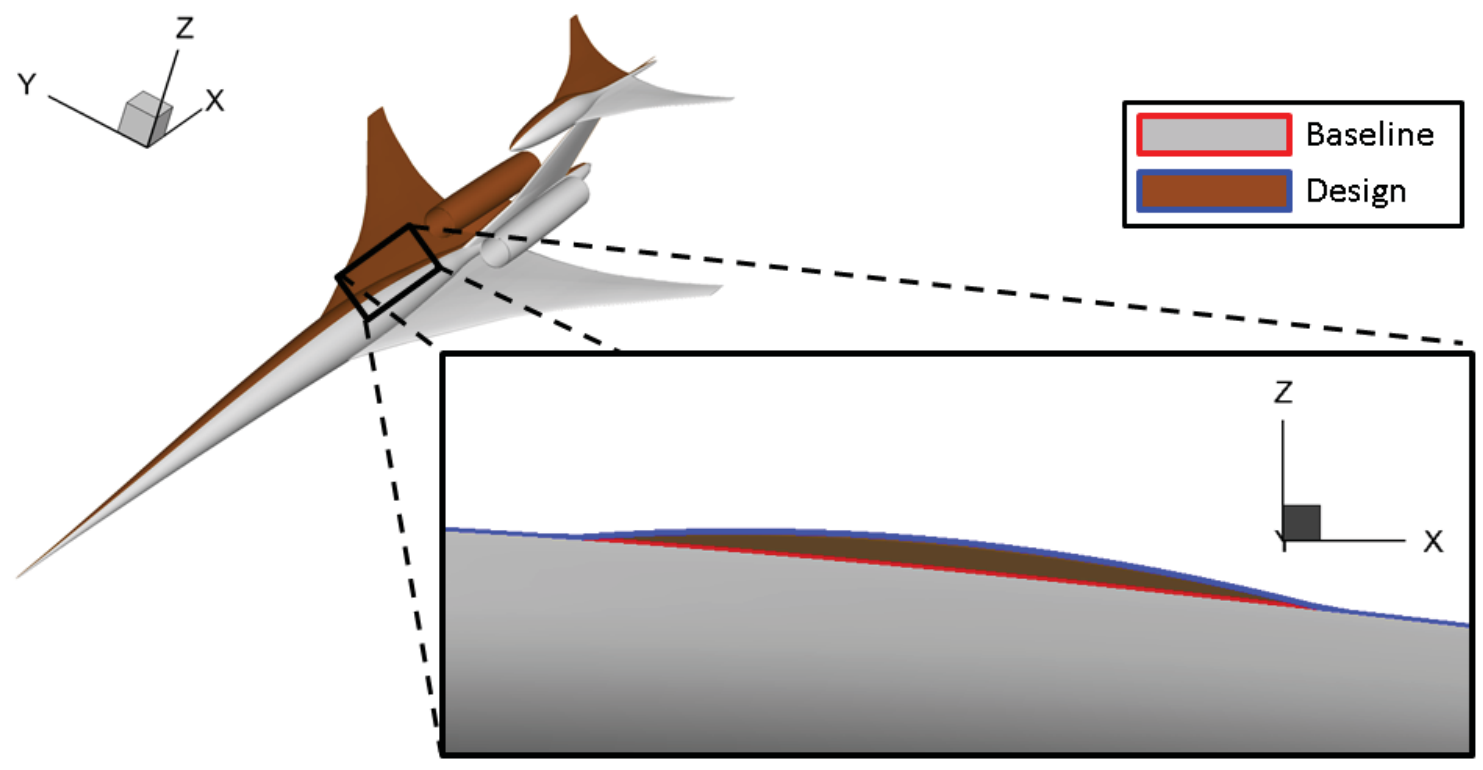

Figure 9. Deformation of fuselage upper region.

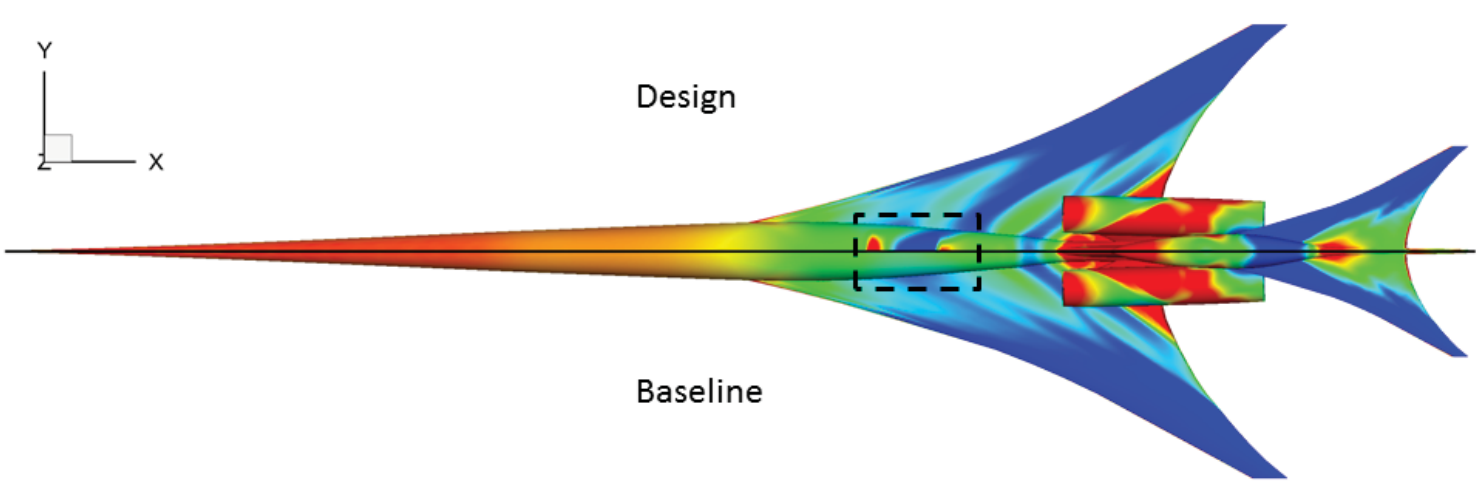

Figure 10. Cart3D surface solution for a deformation on the upper region of the fuselage.

Despite the significant changes in surface pressure distribution, the change in Mach $A_{\mathrm{e}}$ between the design and the baseline remains small. Thus, the mixed $A_{\mathrm{e}}$ prediction is also able to capture the shielding effect provided by the wing on the under-track pressure distribution. Figure A-4 of the Appendix shows the ground signatures corresponding to the equivalent area distributions in Fig. 11. The ground signature predicted for the design in Fig. A-4 shows good agreement with the ground signature that was propagated from the Cart3D off-body pressure distribution. 


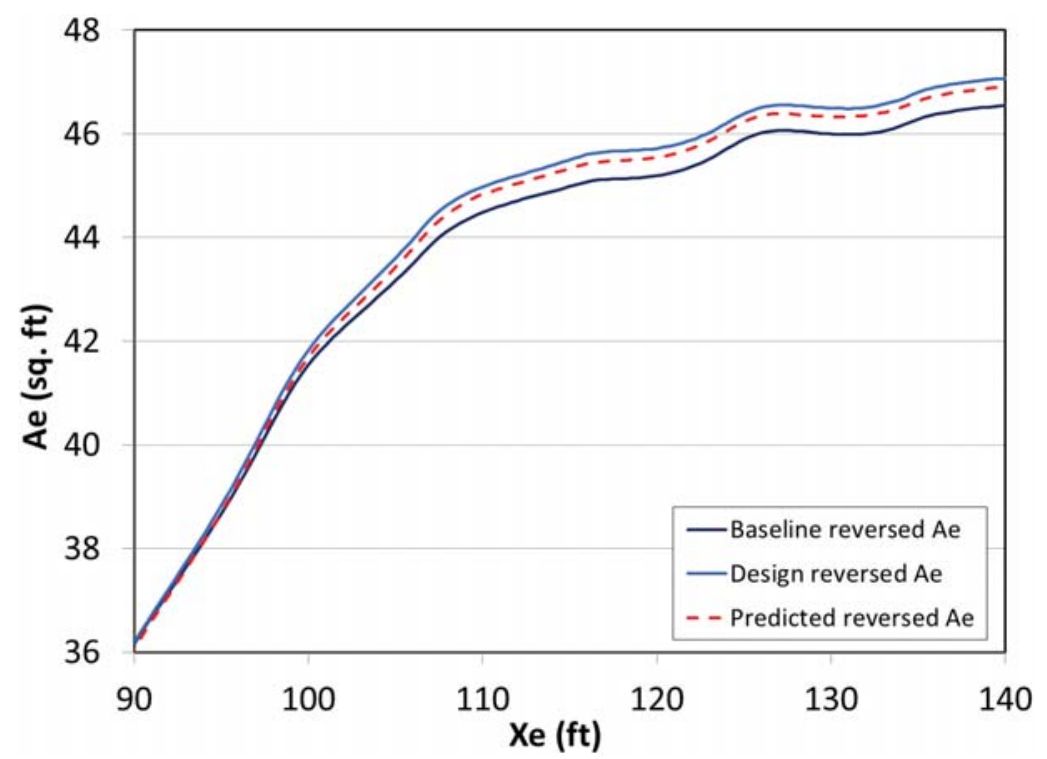

Figure 11. Verification of reversed equivalent area prediction for a fuselage deformation.

\section{Concluding Remarks}

The proposed sonic boom design approach uses a mixed $A_{\mathrm{e}}$ distribution to predict the sonic boom characteristics of a supersonic aircraft obtained from a CFD off-body pressure distribution. The design approach has been verified to be accurate through comparison to sonic boom characteristics obtained from CFD off-body solutions. The first case study demonstrated the capability of the proposed approach for robust low-boom design by verifying the accuracy of the prediction of sonic boom characteristics of a wing twist deformation at under- and off-track locations. The second verification study demonstrated the accuracy of the approach for aft shaping in the presence of a complex flowfield with shock interactions between the nacelle and the tail. The last verification case study for a deformation on the upper region of the fuselage was performed to demonstrate that the design approach is able to predict the shielding effect provided by the main wing.

The sonic boom prediction with mixed $A_{\mathrm{e}}$ is performed at the expense of a single CFD surface solution instead of the more computationally expensive CFD off-body pressure calculation at several body lengths away from the aircraft. This leads to a design iteration cycle that is 40 times faster for the typical CFD solutions and computer systems that are used at the time of this paper. The proposed sonic boom design approach infuses high-fidelity sonic boom analysis into the early stages of the design. This potentially leads to a more efficient design process and a conceptual low-boom configuration that requires fewer compromises as the design matures.

\section{References}

${ }^{1}$ Ordaz, I. and Li, W., "Adaptive Aft Signature Shaping of a Low-Boom Supersonic Aircraft Using Off-Body Pressures," AIAA-2012-0020, January 2012.

${ }^{2}$ Makino, Y. and Kroo, I. M., "Robust Objective Functions for Sonic-Boom Minimization," Journal of Aircraft, Vol. 43, No. 5, 2006, pp. 1301-1306.

${ }^{3}$ Choi, S., Alonso, J. J., and Kroo, I. M., "Multifidelity Design Optimization of Low-Boom Supersonic Jets," Journal of Aircraft, Vol. 45, No. 1, 2008, pp. 106-118.

${ }^{4}$ Makino, Y., Watanuki, T., Kubota, H., Aoyama, T., and Iwamiya, T., "Low-Boom Design Method by Numerical Optimization," AIAA-98-2246, June 1998.

${ }^{5} \mathrm{Li}$, W. and Rallabhandi, S. K., "Inverse Design of Low-Boom Supersonic Concepts Using Reversed Equivalent Area Targets," AIAA-2011-3498, June 2011.

${ }^{6} \mathrm{Li}, \mathrm{W} .$, Shields, E., and Le, D., "Interactive Inverse Design Optimization of Fuselage Shape for Low-Boom Supersonic Concepts," Journal of Aircraft, Vol. 45, No. 4, 2008, pp. 1381-1397.

${ }^{7}$ Plotkin, K. J. and Page, J. A., "Extrapolation of Sonic Boom Signatures from CFD Solutions," AIAA-2002-922, 2002.

${ }^{8}$ Rallabhandi, S. K. and Mavris, D. N., "New Computational Procedure for Incorporating Computational Fluid Dynamics into Sonic Boom Prediction," Journal of Aircraft, Vol. 44, No. 6, 2007, pp. 1964-1971.

${ }^{9}$ Aftosmis, M., Nemec, M., and Cliff, S., "Adjoint-Based Low-Boom Design with Cart3D," AIAA-2011-3500, June 2011. 
${ }^{10}$ Rallabhandi, S. K., "Sonic Boom Adjoint Methodology and its Applications," AIAA-2011-3497, June 2011.

${ }^{11}$ Wintzer, M. and Kroo, I. M., "Optimization and Adjoint-Based CFD for the Conceptual Design of Low Sonic Boom Aircraft," AIAA-2012-0963, January 2012.

${ }^{12}$ Rallabhandi, S. K., "Advanced Sonic Boom Prediction Using Augmented Burger's Equation," AIAA-2011-1278, January 2011.

${ }^{13}$ Plotkin, K. J., "Review of Sonic Boom Theory," AIAA-89-1105, April 1989.

${ }^{14}$ Aftosmis, M. J., "Cart3D Resource Website," http://people.nas.nasa.gov/ aftosmis/cart3d/cart3Dhome.html, [cited April 2013].

\section{Appendix: Comparison of Ground Signatures}

This section contains additional figures of the ground signature comparison for the verification case studies presented in section III. The ground signatures for the baseline and designs are propagated with sBOOM from the off-body pressure distributions calculated with CFD at three body lengths below the aircraft. The predicted $d p / p$ is calculated by converting the predicted reversed $A_{\mathrm{e}}$ distribution into pressure. The predicted ground signatures are calculated by propagating the predicted $d p / p$ with sBOOM.

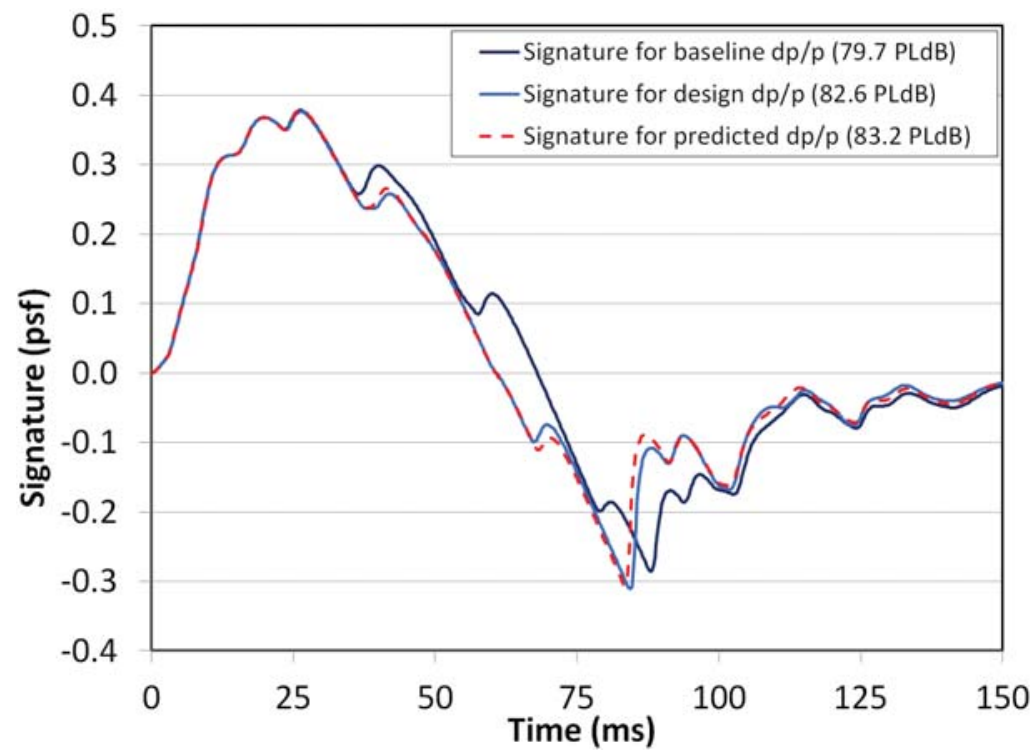

Figure A-1. Under-track ground signature comparison for a wing twist deformation.

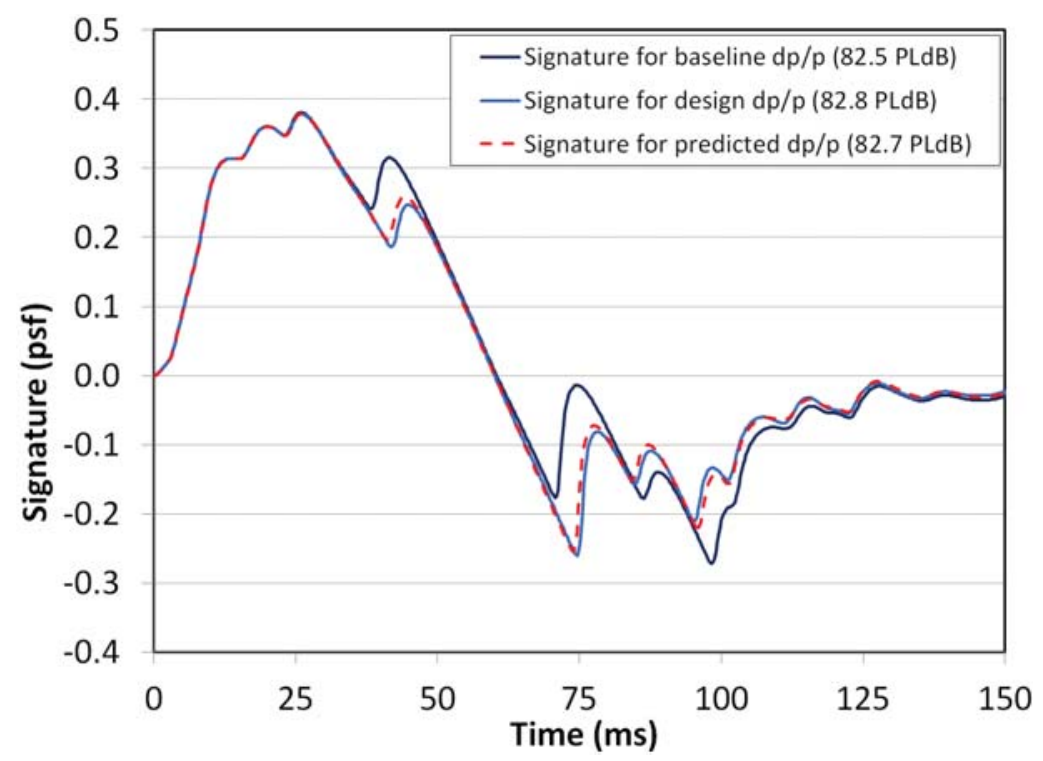

Figure A-2. Off-track ground signature comparison for a wing twist deformation. 


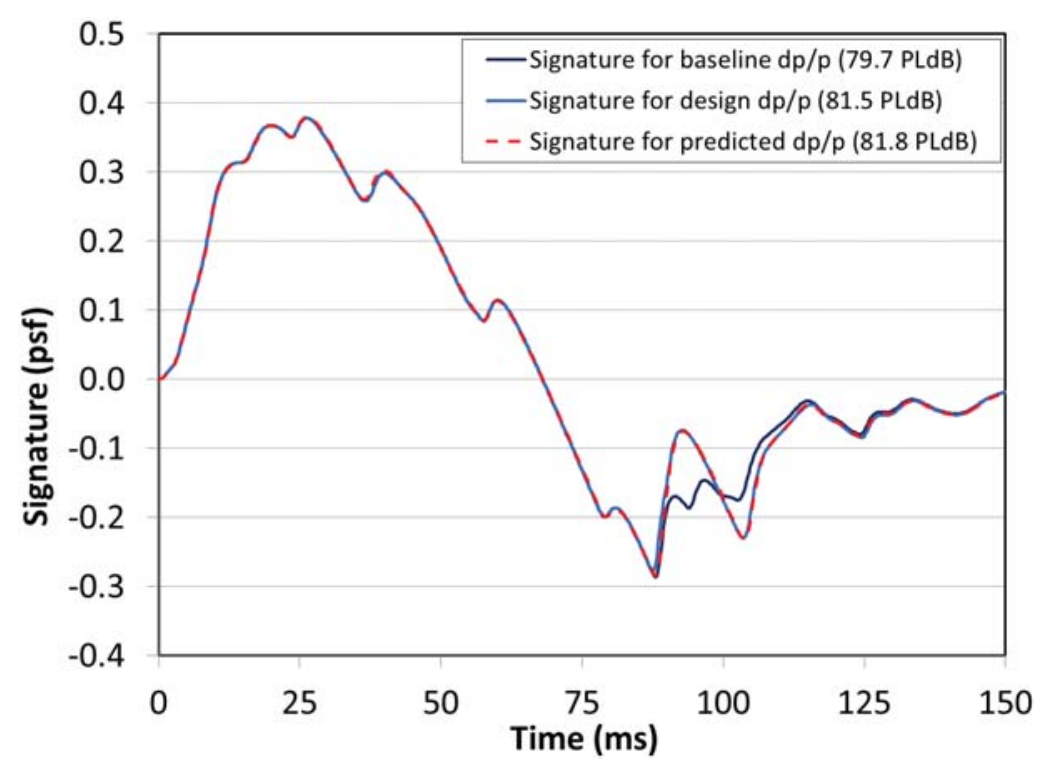

Figure A-3. Under-track ground signature comparison for a horizontal tail camber deformation.

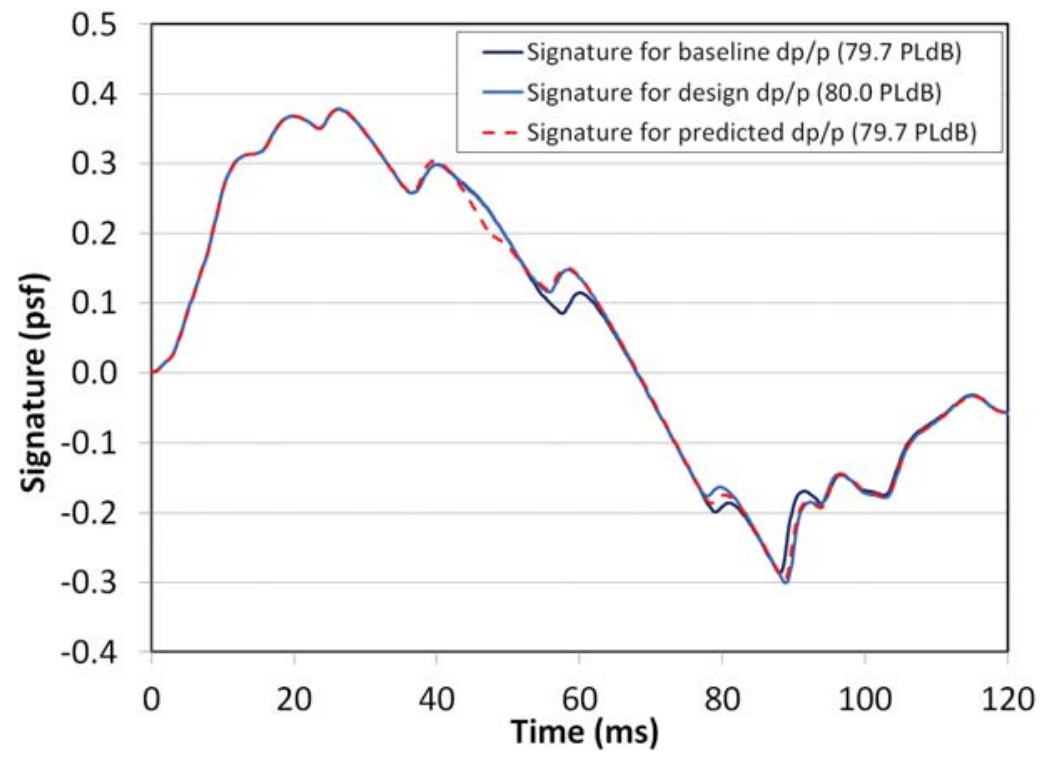

Figure A-4. Under-track ground signature comparison for a fuselage deformation. 